\title{
Maternal and neonatal health services in Sudan: Results of a situation analysis
}

Nahla G. Abdel-Tawab

Population Council

Maha El-Rabbat

Follow this and additional works at: https://knowledgecommons.popcouncil.org/departments_sbsr-rh

Part of the International Public Health Commons, Maternal and Child Health Commons, Obstetrics and Gynecology Commons, Social and Behavioral Sciences Commons, and the Women's Health Commons How does access to this work benefit you? Let us know!

\section{Recommended Citation}

Abdel-Tawab, Nahla G. and Maha El-Rabbat. 2010. "Maternal and neonatal health services in Sudan: Results of a situation analysis," Project brief. Cairo: Population Council. 


\section{Maternal and Neonatal Health}

\section{Services in S U D A N}

Results of a Situation Analysis
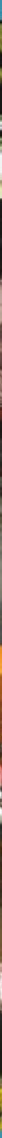

PROJECT BRIEF FEBRUARY 2010

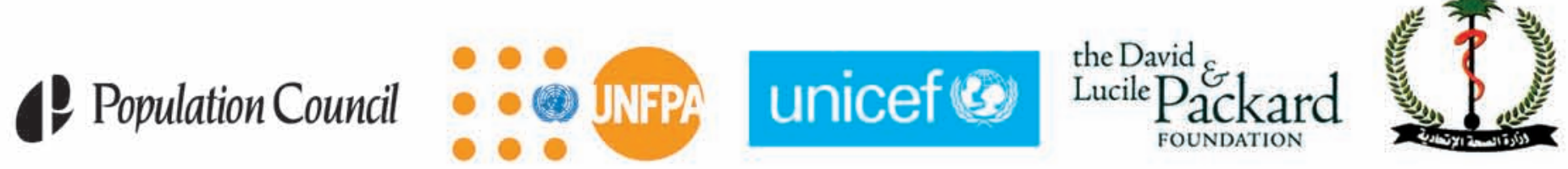




\section{AUTHORS}

Dr. Nahla Abdel-Tawab, Director of Regional Reproductive Program,

Population Council, West Asia and North Africa Regional Office

Dr. Maha El-Rabbat, Professor of Community Medicine, Cairo University

\section{DESIGN}

Gihan Hosny, Reproductive Health Program Administrator

\section{SUGGESTED CITATION}

Abdel-Tawab, Nahla and Maha El-Rabbat. 2010. "Maternal and Neonatal Health Services in Sudan: Results of a Situation Analysis". Project Brief. Cairo, Egypt: Population Council

\section{PHOTO CREDIT}

Courtesy of Photoshare. http://www.photoshare.org/

This project brief is based on the results of a Situation Analysis (SA) study that was done collaboratively by the Population Council and Sudan Ministry of Health (MOH) with Funds from UNFPA, UNICEF, and Packard Foundation. The above study was conducted under the leadership of Dr. Eldaw Suliman and coordination of Dr. Khaled Nada at the Population Council. The SA study would not have been possible without the support and guidance of MOH federal officials: Dr. Mohamed Malik Al Abbasi, Dr. El-Tayeb Ahmed Elsaid, Dr. Lamia Eltigani and Dr. Hanan Mokhtar Abdo. The cooperation and assistance of MOH state officials in the seven study states (Gadarif, Gezira, Kassala, Khartoum, North Kordofan, South Kordofan and South Darfur) are deeply appreciated. Last, we are grateful to the reviewers of this Program Brief: Dr. John Townsend, Dr. Ian Askew and Ms.Safaa El-Kogali.

This publication is made possible by the generous support of the Packard Foundation (grant no. 2009-33290). The views expressed in this brief are the responsibility of the Population Council and do not necessarily reflect those of MOH/Sudan, Packard Foundation, UNFPA or UNICEF.

\section{(C) 2010 The Population Council, Inc.}


C ONTENTS

\begin{tabular}{r|l} 
& Background \\
\hline 2 & Methodology \\
\hline 3 & Findings \\
\hline 10 & Project Implications \\
\hline 14 & References \\
\hline
\end{tabular}




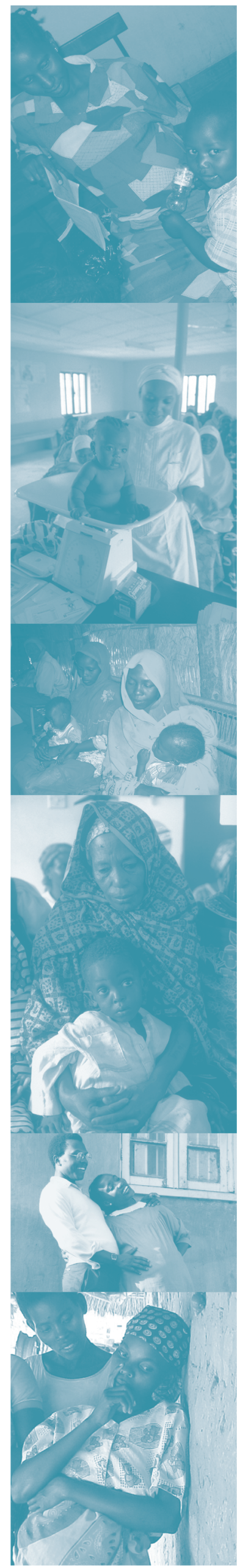

\section{B A C K G R O U N D}

With a maternal mortality ratio of 1,107 per 100,000 live births, Sudan has one of the highest maternal death rates in the world (Sudan Government of National Unity and Government of Southern Sudan, 2006). Moreover, for every woman who dies, approximately 20 more suffer long-lasting injuries, or disabilities such as obstetric fistula, uterine prolapse, infertility and depression. The main direct causes of maternal death in Sudan are hemorrhage, infection, pregnancy-induced hypertension and unsafe abortion, while malaria, anemia and hepatitis contribute indirectly (Sudan Government of National Unity and Government of Southern Sudan, 2006; Kinaro et al., 2009). Maternal death is often associated with neonatal death. The infant mortality rate in Sudan is estimated at 81 per 1000 live births and about half of those are neonatal deaths that occur during the first month of life (Sudan Government of National Unity and Government of Southern Sudan, 2006). Neonatal deaths are caused mainly by asphyxia, preterm birth and sepsis.

Maternal and neonatal mortality can be reduced by ensuring access to voluntary family planning to space births, provision of adequate antenatal care, ensuring skilled attendance at delivery, backed by emergency obstetric care when needed. http://www.unfpa.org/safemotherhood/mediakit/documents/fs/factsheet1_eng.pdf The United Nations recommends the four pillars of safe motherhood as: (1) family planning (FP), (2) antenatal care (ANC), (3) skilled birth attendance (skilled health personnel, commodities, drugs, and equipment) and (4) emergency obstetric and neonatal care. Moreover, it is crucial to overcome the three main delays in accessing health services: 1) delay in recognizing danger signs and in making the decision to seek medical care; 2) delay in arrival at a health facility; and 3) delay in the provision of adequate care at the health facility (see Text Box 1).

High maternal and neonatal mortality rates in Sudan suggest gaps in access to and quality of maternal and neonatal health services. This project brief highlights issues in the availability and quality of maternal and neonatal health services and provides recommendations to help policy makers improve the quality of services and reduce maternal and neonatal deaths in Sudan.

\section{Text Box 1: The Three Delays Model}

When it comes to preventing maternal mortality and disability, timing is critical: although post-natal haemorrhage can kill a woman in less than two hours, most other complications have a window of 12 hours or more during which to obtain life-saving emergency care. The "three delays" model is a useful yardstick to manage obstetric complications, and to design programmes to prevent maternal death or injury.

The three delays are: 1. Delay in deciding to seek care, 2. Delay in reaching appropriate care, 3. Delay in receiving care at health facilities

The first two relate directly to the issue of access to care - including family pressure to give birth at home either because of social or community pressure or owing to inadequate funds for transportation. The third relates to inadequacies within the health care system itself. This could be lack of properly trained personnel, transfusion equipment and other infrastructural inadequacies. Unless the three delays are addressed, no safe motherhood programme can succeed.

Source: UNFPA: No Woman Should Die Giving Life:

http://www.unfpa.org/safemotherhood/mediakit/documents/fs/factsheet4_eng.pdf (accessed on February 20, 2010) 


\section{E T H O D O L O G Y}

This brief is based on the results of a situation analysis (SA) of reproductive health services that was conducted in seven states to understand programmatic factors that contribute to the current health status of women and newborns in Sudan. The study was done collaboratively by the Population Council and Sudan Ministry of Health $(\mathrm{MOH})$ with funds from UNFPA, UNICEF and the Packard Foundation and was implemented in the following states: Khartoum, Kassala, Gadarif, Gezira, North Kordofan, South Kordofan and South Darfur. The study collected data from a total of 348 primary, secondary and tertiary care facilities to assess their readiness for providing reproductive health care services and the quality of services provided. In addition, interviews were conducted with 909 providers who offer reproductive health services (physicians, nurses, midwives, health officers and others), 1029 village midwives (VMWs), 1,313 clients seeking care at the study facilities and 1,012 antenatal care clients. More information on the study methodology can be obtained from any of the SA study reports listed in the reference section.

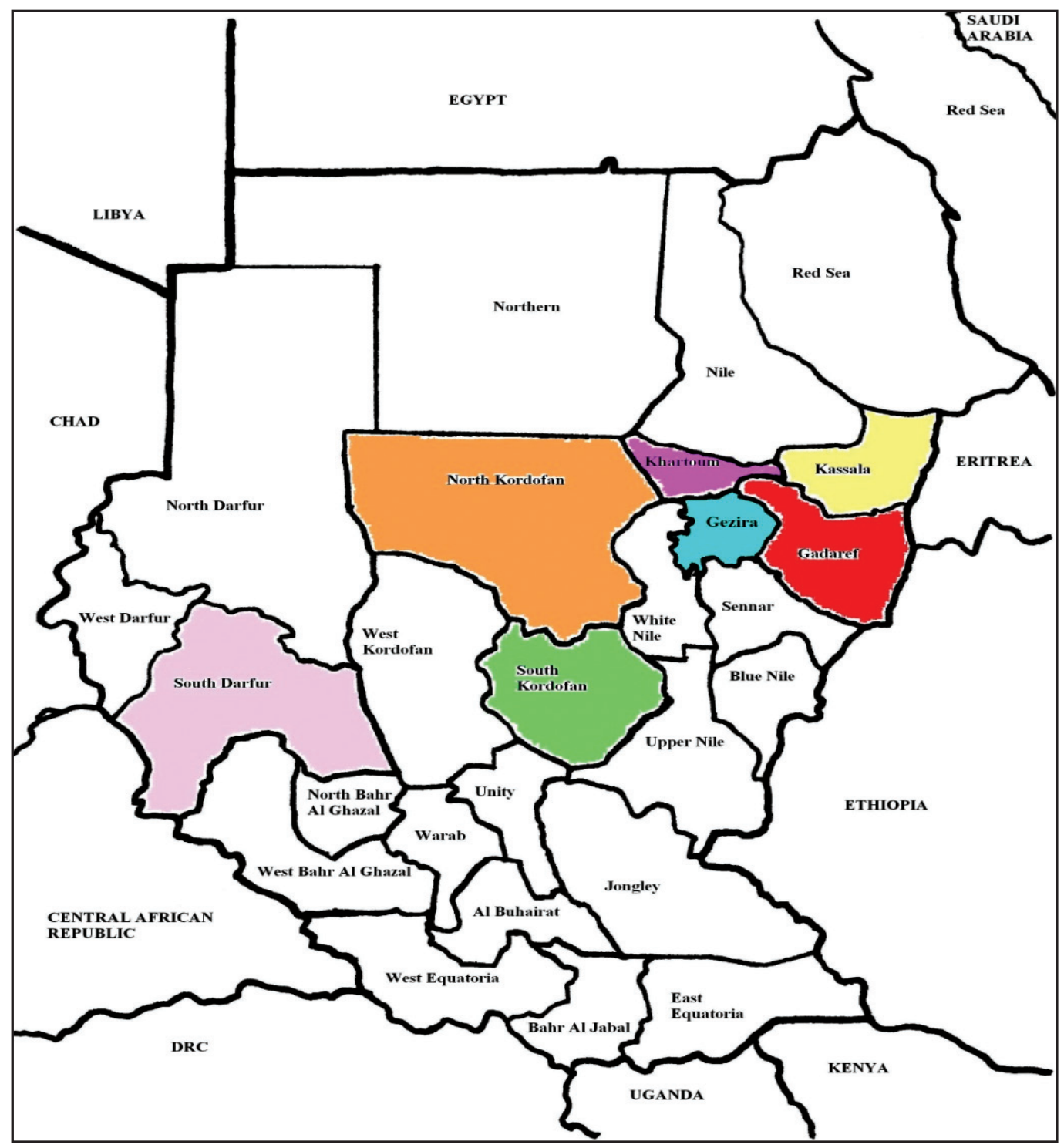




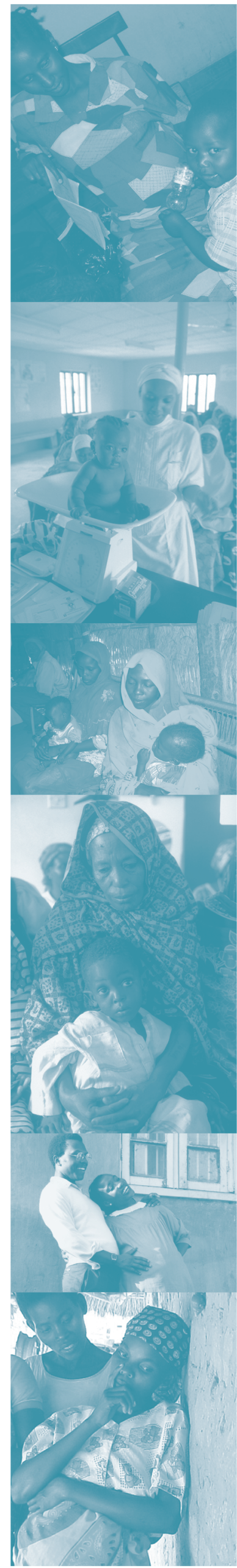

\section{F I N D I N G S}

\section{Availability and Accessibility of Reproductive Health Services}

\section{Nurses and nurse midwives are the key element of reproductive health services in surveyed facilities}

The study revealed uneven distribution of RH staff across the seven states, with Khartoum having the highest concentration of reproductive health staff (an average of 28 per facility) and Kassala having the lowest concentration (average of 10 per facility). As to staff composition, Figure 1 shows that nurses and nurse midwives are a key element of reproductive health services, accounting for an average of 43 percent of staff providing reproductive health services (range: 32 percent in North Kordofan to 57 percent in South Darfur), while general practitioners accounted for about 12 percent (range: 4 percent in South Darfur to 15 percent in Kassala). A shortage of specialized Obstetricians and Gynecologists $(\mathrm{Ob} / \mathrm{Gyn})$ physicians (5 percent) is noted in all seven states. While $\mathrm{Ob} / \mathrm{Gyn}$ physicians constitute 7 percent of the health workforce in the surveyed facilities in Khartoum, they only constitute 2 percent of the workforce in both South Kordofan and South Darfur states.

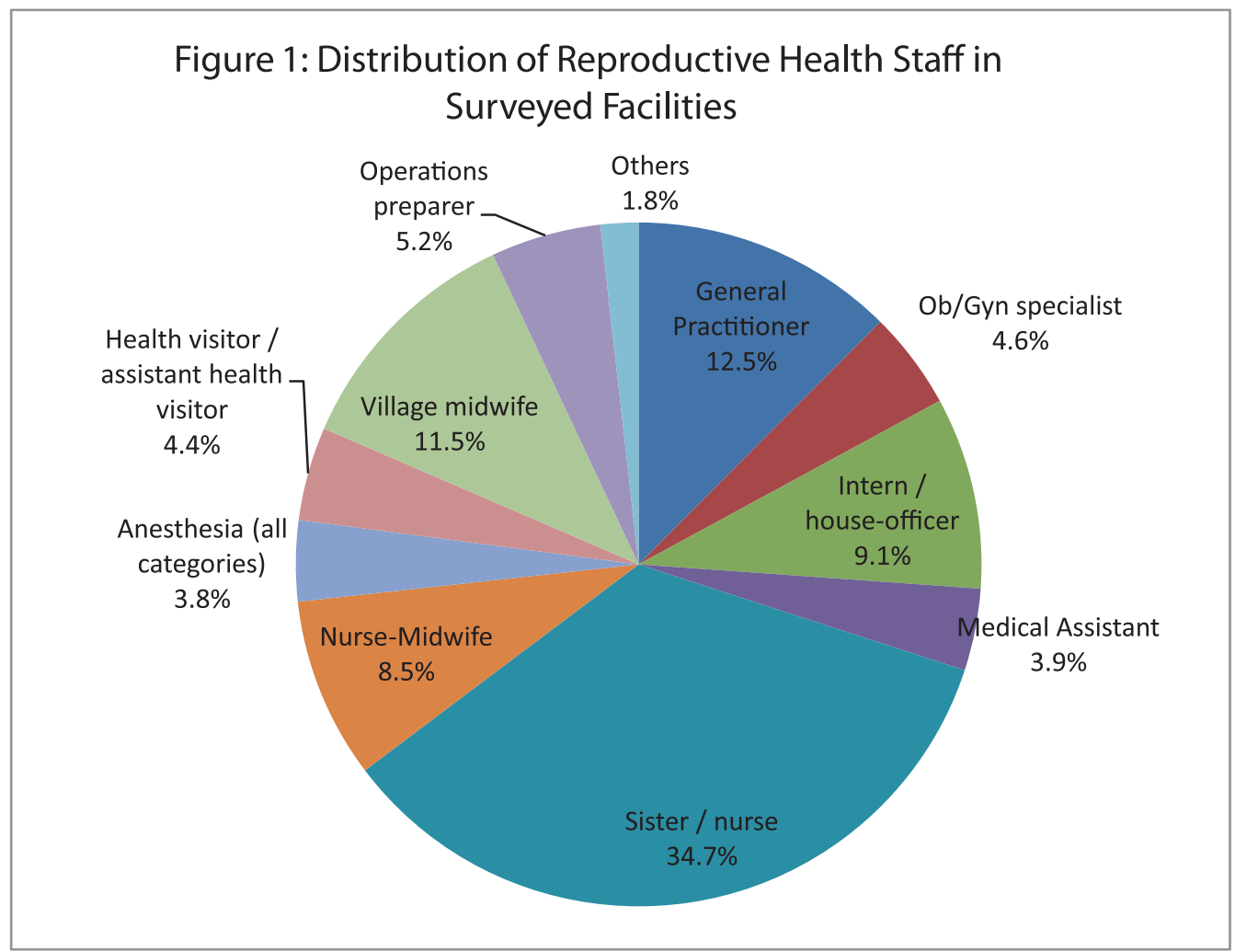

Ease of access to health services is an important factor that affects maternal health outcomes. According to the majority of clients interviewed ( 83 percent), most facilities were accessible by public transportation, except for those in 
North Kordofan and South Darfur where facilities were less accessible by public transportation (50 percent and 57 percent, respectively). The average time taken by clients to reach facilities ranged from 15 minutes in Gezira and South Kordofan to 29 minutes in South Darfur states.

Due to the emergency nature of labor and delivery services, including the ability to handle complications, they should be available 24 hours a day. Overall, only 29 percent of facilities were open 24 hours a day, with availability somewhat higher in the states of Gadarif and Gezira (37 and 36 percent, respectively).

\section{Family Planning}

\section{Limited access to family planning services in the study states}

Family planning services are essential to promote maternal health and lower maternal mortality. Contraceptive use is very low in Sudan, with a contraceptive prevalence rate (CPR) of around 8 percent for any form of family planning (Sudan Government of National Unity and Government of Southern Sudan, 2006). Not surprisingly, Sudan has one of the highest fertility rates in the Eastern Mediterranean region (5.9 births per woman).

Figure 2 shows that more than three quarters of health facilities ( 79 percent) provided FP services in the 6 months prior to the survey. The highest percentage of facilities providing family planning services was reported in Khartoum state (91 percent) and the lowest in South Kordofan state (62 percent). These results are consistent with Sudan Household Survey (SHHS) data which showed CPR to be highest in Khartoum state (20 percent) and lowest in South Kordofan state (1.9 percent).

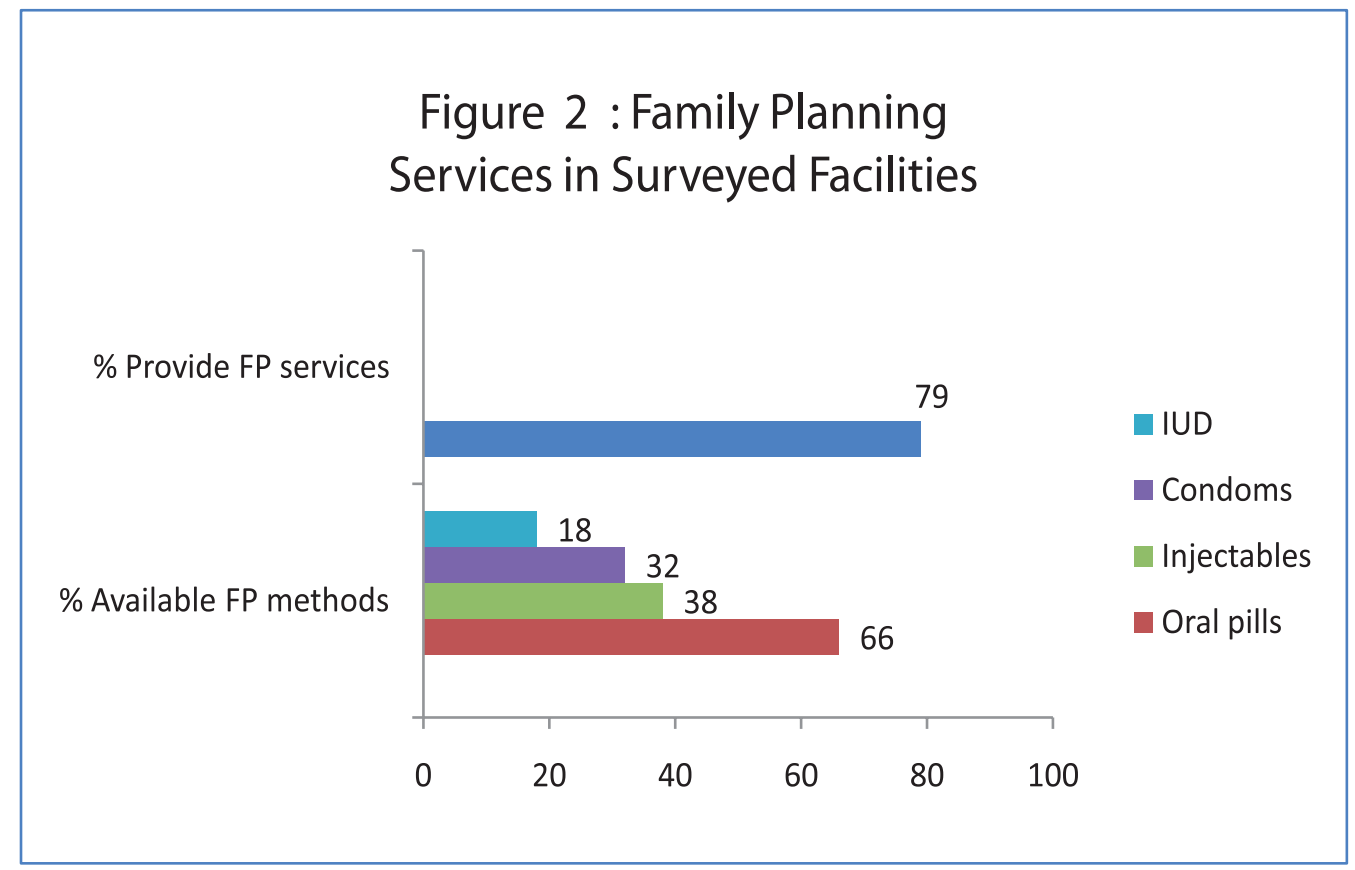




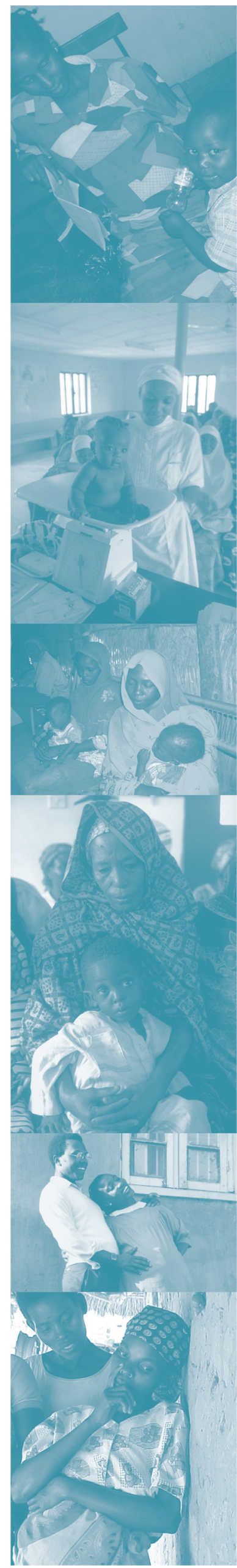

Among the range of contraceptive methods, oral pills were the most likely to be provided in the facilities (66 percent) and the Intra-Uterine Device (IUD) the least likely, found in fewer than one in five facilities (18 percent). Availability of equipment for providing family planning services was also limited. For example, a vaginal speculum, which is needed for a pelvic examination and for IUD insertion, was present in only one-third of facilities in North Kordofan, South Kordofan, and South Darfur and in fewer than one-fifth of facilities in Kassala.

It is noteworthy that only half of the interviewed providers reported having received in-service training in family planning, with less than one-quarter of providers reporting receiving in-service training in IUD insertion / removal, while only 2.6 percent of providers in Kassala reporting receiving such training.

\section{Antenatal Care}

\section{Pregnant women in the study states seldom receive counseling on birth spacing or birth preparedness}

Antenatal care visits provide a vehicle for important interventions and programs to support the health and wellbeing of the pregnant woman and her unborn child. The World Health Organization (WHO) recommends four antenatal care visits, which at a minimum should include the following services: (1) blood pressure measurement, (2) urine testing for bacteruria and proteinuria, (3) blood testing to detect syphilis and severe anemia and, (4) tetanus immunization. In addition, pregnant women should receive information counseling on self-care at home, nutrition, breastfeeding, family planning, birth planning, advice on danger signs during pregnancy/delivery and emergency preparation (Sudan Government of National Unity and Government of Southern Sudan, 2006; WHO, 2009).

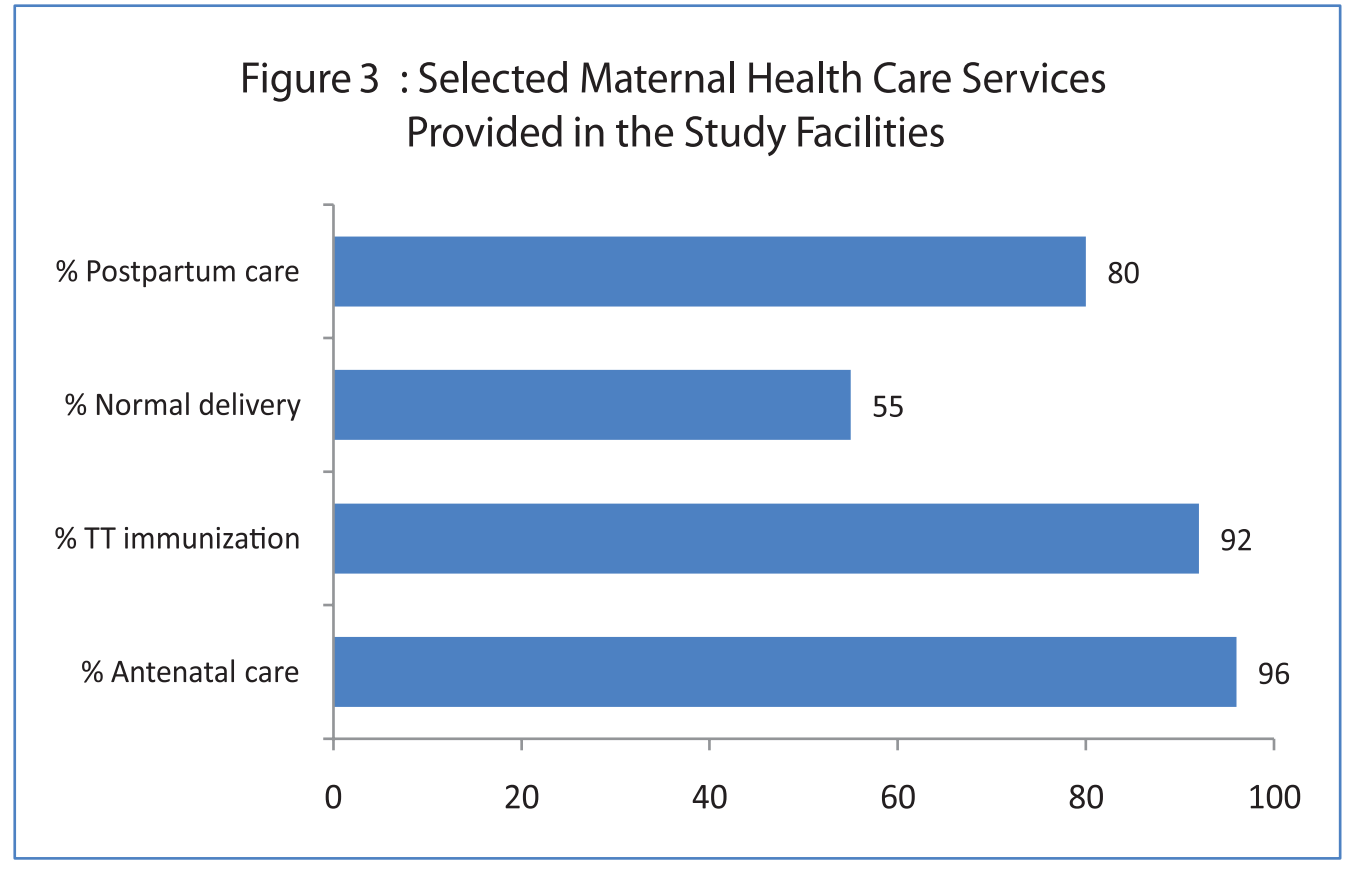


Almost all facilities (96 percent) offered ANC services and Tetanus Toxoid (TT) immunization (92 percent) (Figure 3). Although 8 of 10 facilities provided postpartum care, the levels varied by state, where it reached the highest level in Khartoum (91 percent) and lowest in Kassala (36 percent). Basic equipment for the provision of ANC was available in most of the facilities. For example, more than 90 percent had a functioning blood pressure cuff and about three-quarters had a functioning adult scale (70 percent). Diagnostic imaging services for fetal monitoring and diagnosis of complications were lacking, as only one-third of secondary and tertiary care facilities had a functioning ultrasound machine. Lab tests, such as hemoglobin analysis and urine analysis, were offered in more than 90 percent of facilities, while $\mathrm{Rh} /$ blood typing was offered in two-thirds of surveyed facilities and even one-third of facilities in Kassala.

Clients who received ANC in the facilities were more likely to receive lab tests and physical exams than counseling and health education (Figure 4). The most commonly received antenatal care services were diagnostic urine analysis (77 percent) and blood sampling (74 percent). Although the mean duration of pregnancy of the clients was fairly high (24- 28 weeks), counseling on birth preparedness was rather deficient. This has important implications, given that more than three-quarters of deliveries (77 percent) in Sudan take place at home (Sudan Government of National Unity and Government of Southern Sudan, 2006). For example, less than one-third of clients were advised to deliver at a health facility ( 26 percent) or were told how to get to a heath facility if a problem
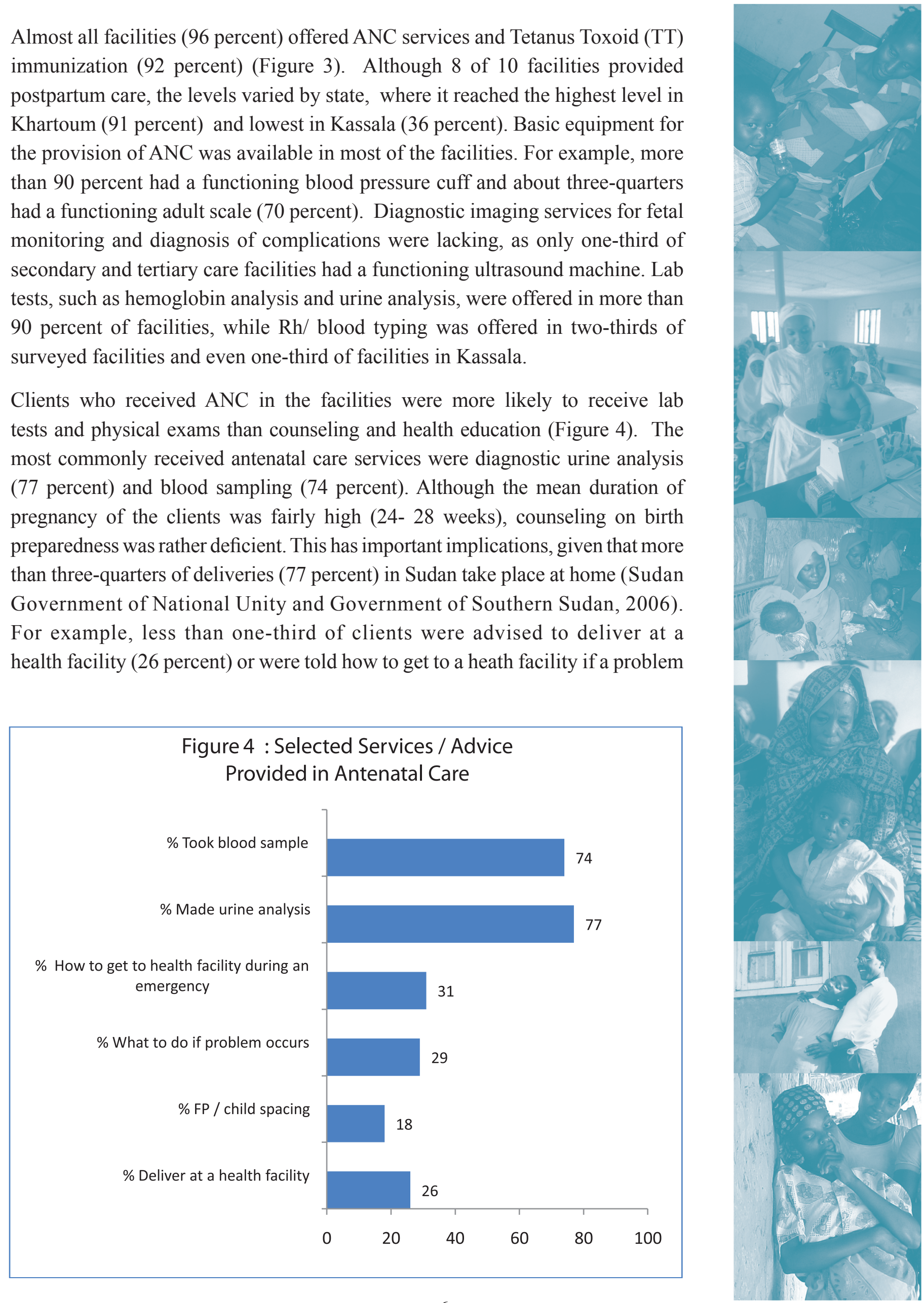


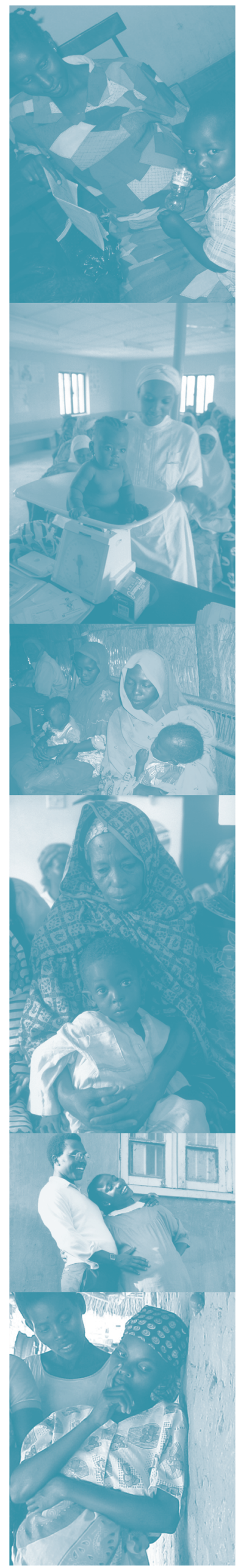

occurs during delivery (31 percent), while less than one in five antenatal care clients were told about family planning / birth spacing (18 percent) to prevent unplanned or closely spaced pregnancies.

\section{Skilled Birth Attendance}

\section{Inadequate knowledge and skills of birth attendants in the study states}

Three-quarters of maternal deaths occur during delivery and the immediate postpartum period (Sudan Government of National Unity and Government of Southern Sudan, 2006). Thus the availability of a skilled health worker with midwifery skills (along with commodities, drugs, equipment), as well as adequate transportation for referral in case of an emergency, are crucial for saving maternal and neonatal lives. According to results of the SHHS, only half of all births in Sudan are delivered by skilled personnel. Within the study states, South Darfur had the lowest proportion of assisted deliveries (40 percent), while Khartoum had the highest proportion ( 85 percent).

The SA study showed that slightly more than half (55 percent) of the facilities had provided normal delivery services in the six months prior to the survey (Figure 3). Normal delivery services were far more likely to be provided in secondary and tertiary level facilities than in primary level facilities ( 90 percent versus 32 percent, respectively).

The great majority of staff in the study facilities had received basic training in normal delivery care ( 95 percent), postpartum care ( 89 percent) and newborn resuscitation ( 84 percent), but only half (55 percent) had received basic training in management of abortion complications. It is noteworthy that in their basic training, one quarter of providers were not trained on active management of third stage of labour (AMTSL) (22 percent), while two thirds did not receive training in administration of magnesium sulfate.

In-service training was limited; less than half of the providers had received inservice training in normal delivery care (44 percent) or postpartum care (45 percent) and an even smaller proportion had received in-service training in the management of abortion complications ( 24 percent). For those who had received in-service training, the duration since that training was fairly long, ranging from 3 years in Kassala to 11 years in Khartoum.

Despite this training, providers' knowledge related to safe delivery and identification of danger signs was deficient in some of the study states. For example, only 14 percent of doctors in South Darfur considered systolic blood pressure less than $90 \mathrm{~mm}$ as a warning sign during delivery while less than onequarter (23 percent) of doctors in South Kordofan considered labour for more than 24 hours as a danger sign. 
Overall, VMWs attended one in five deliveries in Sudan (19.7 percent) while among the study states they attended nearly one in three deliveries in South Darfur and Kassala (36 percent and 30 percent, respectively). VMWs who worked in the catchment area of the study facilities had on average 11 years experience in attending deliveries. More than 90 percent of VMWs had received pre-service training in normal delivery and postpartum care. However, only onethird had received in-service training in delivery care (35 percent), postpartum care (32 percent) or new born resuscitation ( 29 percent). Duration since last training was quite long, with a median duration of 9 years.

VMWs' knowledge of danger signs during pregnancy or delivery was alarmingly low. For example, only one-fifth of VMWs in South Darfur recognized severe headache as a warning sign during pregnancy, while only one percent of those in South Kordofan recognized a pulse rate greater than 110 per minute as a danger sign during delivery. It is worth mentioning that VMWs were not regularly supervised by the state health department. Slightly more than half of the VMWs (56 percent) reported receiving advice and guidance from $\mathrm{SMOH}$ at least once in the past five years, while a smaller proportion (31 percent) received medical supplies or equipment from $\mathrm{SMOH}$.

\section{Emergency Obstetric Care (EMOC)}

\section{EMOC services are lacking in many secondary and tertiary care facilities}

Birth complications are common in Sudan. Nationally, more than 1 in 3 women suffer from prolonged labour and high fever, 1 in 10 women suffer from convulsions and 1 in 4 women suffer from excessive bleeding. The incidence of complications is substantially higher in South Darfur state, where 46 percent of women experienced prolonged labour and 30 percent experienced excessive bleeding (Sudan Government of National Unity and Government of Southern Sudan, 2006). This situation warrants the presence of enough facilities that can provide emergency obstetric care (EMOC) as well as adequate referral mechanisms.

EMOC refers to a set of interventions for women who are suffering from complications during labour or delivery that require professional assistance. It requires the availability of skilled staff, a reliable transportation system, adequate supply of drugs and functioning equipment. WHO guidelines distinguish between two levels of emergency obstetric care: Basic Emergency Obstetric Care (BEOC) and Comprehensive Emergency Obstetric Care (CEOC). BEOC can be provided at a health center and does not require an operating theater. Key interventions include administration of antibiotics, oxytocins and anticonvulsants, manual 


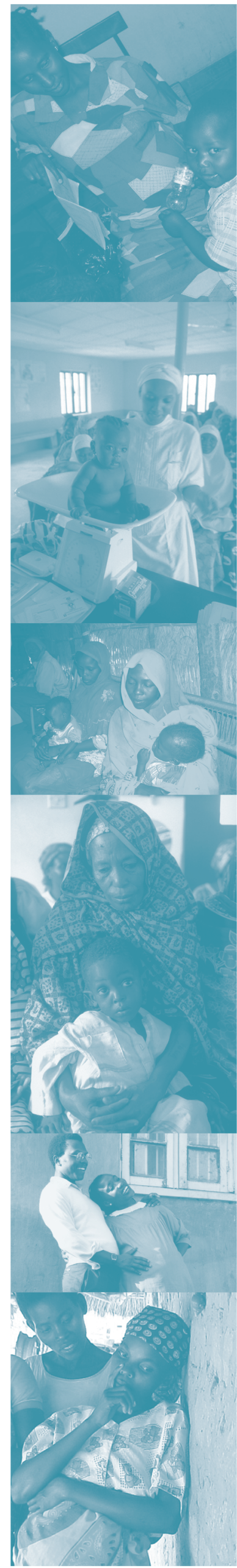

removal of the placenta, assisted vaginal delivery and newborn resuscitation. CEOC includes BEOC as well as additional actions such as surgery (e.g. for a Caesarean section), safe blood transfusion and oxygen for the newborn. CEOC requires an operating theater hence is provided in secondary and tertiary care facilities. (WHO, 2009; Prata et al., 2009).

In general, the secondary and tertiary care facilities surveyed managed a wide spectrum of complicated cases in the six months preceding the survey, primarily postpartum hemorrhage (81 percent), puerperal sepsis (81 percent) and complications of abortion (75 percent).

Table 1 shows that two-thirds of the secondary and tertiary care facilities surveyed provided Caesarean section (67 percent), while about three-quarters provided instrumental deliveries (72 percent). However, striking variations existed across states, with South Darfur and Gadarif facilities less likely than the other states to offer Caesarean section or instrumental delivery. Lack of blood bank services, an intensive care unit (ICU) and a neonatal intensive care unit (NICU) in many of the facilities is a concern. For example, only 8 percent of secondary and tertiary care facilities in South Darfur had a functioning ICU or NICU, while none of the facilities in Kassala had either.

\begin{tabular}{|c|c|c|c|c|c|c|c|c|}
\hline $\begin{array}{l}\text { CEOC } \\
\text { services }\end{array}$ & $\begin{array}{l}\mathrm{KH} \\
\mathrm{N}=22\end{array}$ & $\begin{array}{l}\mathrm{KA} \\
\mathrm{N}=9\end{array}$ & $\begin{array}{l}\mathrm{GA} \\
\mathrm{N}=16\end{array}$ & $\begin{array}{l}\mathrm{GE} \\
\mathrm{N}=35\end{array}$ & $\begin{array}{l}\text { N. KO } \\
\mathrm{N}=18\end{array}$ & $\begin{array}{l}\text { S. KO } \\
N=14\end{array}$ & $\begin{array}{l}\text { S. DA } \\
N=24\end{array}$ & $\begin{array}{l}\text { Total } \\
N=138\end{array}$ \\
\hline C-section & 73.0 & 56.0 & 44.0 & 74.0 & 89.0 & 93.0 & 37.5 & 67.0 \\
\hline $\begin{array}{l}\text { Instrumental } \\
\text { delivery }\end{array}$ & 73.0 & 78.0 & 50.0 & 91.0 & 77.0 & 93.0 & 37.5 & 72.0 \\
\hline $\begin{array}{l}\text { Blood bank } \\
\text { services }\end{array}$ & 77.0 & 44.0 & 25.0 & 71.0 & 56.0 & 57.0 & 33.0 & 56.0 \\
\hline $\begin{array}{l}\text { Intensive } \\
\text { care unit }\end{array}$ & 5.0 & 0.0 & 0.0 & 14.0 & 17.0 & 29.0 & 8.0 & 11.0 \\
\hline $\begin{array}{l}\text { Neonatal int. } \\
\text { care unit }\end{array}$ & 5.0 & 0.0 & 19.0 & 14.0 & 11.0 & 7.0 & 8.0 & 10.0 \\
\hline Note: & \multicolumn{4}{|c|}{$\begin{array}{l}\mathrm{KH}=\text { Khartoum } \\
\mathrm{KA}=\text { Kassala }\end{array}$} & \multicolumn{4}{|c|}{$\begin{array}{l}\text { N. KO }=\text { North Kordofan } \\
\text { S. KO }=\text { South Kordofan }\end{array}$} \\
\hline
\end{tabular}

Basic training on the management of complicated deliveries was lacking among a significant proportion of providers in the secondary and tertiary level facilities that are expected to manage those complications. For example, only half of the secondary and tertiary care providers in the surveyed facilities received training in C-section, instrumental delivery or management of complications of abortion 
(45 percent, 49 percent and 56 percent, respectively). The situation in Gadarif and South Darfur is even more disturbing, with only one-quarter of providers in Gadarif (26 percent) and 17 percent of providers in South Darfur reporting receiving basic training in $\mathrm{C}$ - section.

A shortage of some essential life saving drugs was found and drug availability varied widely by state. For example, drugs used for the prophylaxis or management of postpartum hemorrhage (e.g. oxytocin) were present in 60 percent of facilities in Gezira but only 20 percent of facilities in South Darfur. Similarly, magnesium sulfate was only present in one-third of facilities (36 percent) overall, and was especially lacking in South Darfur (10 percent), Kassala (23 percent) and South Kordofan (26 percent).

Availability of ambulance vehicles and telecommunication services is crucial for the timely referral of complicated cases and for getting mothers to attended delivery facilities. However, a lack of these facilities was noted especially in Gadarif and Kassala, where they were available in only 9 percent and 13 percent of surveyed facilities, respectively. Likewise, a lack of working telephones poses a major obstacle to the timely referral of cases. Except for Khartoum state, where telecommunication was available in 73 percent of facilities, this service was available in only 18 percent to 39 percent of facilities in the other states.

It is worth mentioning that one-third of providers reported difficulty in referring emergency cases to higher levels of care. Providers in Kassala, South Darfur and South Kordofan were more likely to report difficulties compared to those in other states. Moreover, one in five VMWs (21 percent) reported experiencing difficulty in referring complicated cases to health facilities, while 44 percent of VMWs in South Darfur reported such problem.

\section{PRO JEC T I M P L I C A T I O N S}

Pregnancy and childbirth remain serious life threatening events for many women in Sudan. The situation analysis has pointed to a number of gaps in the availability and quality of maternal and neonatal health services, which contribute to the high levels of maternal and neonatal mortality in Sudan. Major policy changes, in addition to specific services, are necessary if Sudan is to meet MDG 5 of reducing maternal mortality ratio by 75 percent by the year 2015 . The states of South Darfur and South Kordofan tend to have lower quality of services and hence deserve additional efforts. 


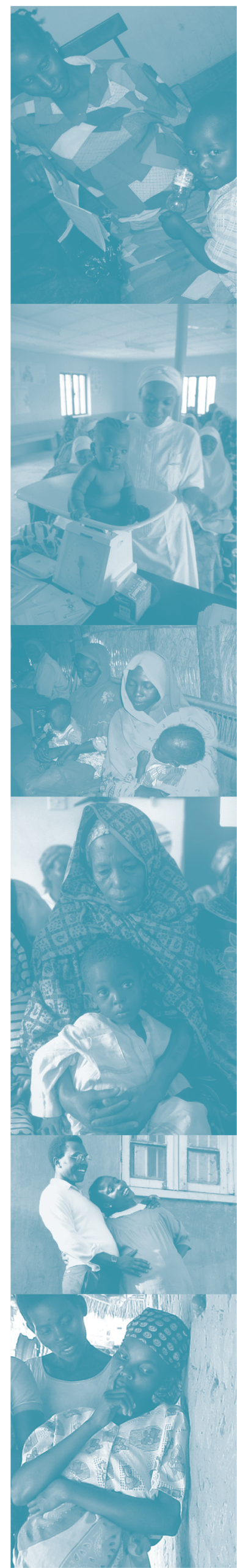

International organizations have identified three key measures to reduce maternal and neonatal mortality: (1) universal access to contraception to avoid unintended and mis-timed pregnancies; (2) access to skilled care during delivery; and (3) rapid access to quality emergency obstetric care when needed (UNFPA, 2009) (see Text Box 2). We will discuss each of those measures below and see how they can be applied within the context of Sudan.

Universal access to contraception: Ensuring access to and use of voluntary family planning could reduce maternal deaths by a third and child deaths by as much as 20 percent (Cleland, 2006). By reducing unwanted pregnancies, family planning services can result in reducing the number of women who seek unsafe abortion. Family planning can also reduce pregnancies that occur when the woman is too young, too old or that are closely spaced. Research from many countries has shown that offering family planning services during the antenatal and postpartum period is associated with increased uptake (Abdel-Tawab, N.; Loza, S. Zaki, A. 2008; Khan et al. 2008; Vernon 2008;).

\section{Text Box 2: Reducing Maternal Mortality}

Working for the survival of mothers is a human rights imperative.

It also has enormous socio-economic ramifications - and is a crucial international development priority. Both the International Conference on Population and Development and Millennium Development Goals call for a 75 per cent reduction in maternal mortality between 1990 and 2015. This three-pronged strategy is key to the accomplishment of the goal:

- All women have access to contraception to avoid unintended pregnancies

- All pregnant women have access to skilled care at the time of birth

- All those with complications have timely access to quality emergency obstetric care

Source: UNFPA: Safe Motherhood: http://www.unfpa.org/public/mothers

A wide range of family planning methods needs to be available in all health facilities to ensure effective and consistent use of contraception. Condoms should be available and promoted because they provide dual protection (i.e. against pregnancy and STIs). Health care providers need to receive refresher training in family planning, especially IUD insertion and removal. Moreover, the problem of an insufficient number of doctors in some states, especially rural areas, needs to be addressed. For example, policies that prohibit non-physicians from providing family planning services could be revised to allow nurses and village midwives to provide family planning services. WHO has summarized the 
evidence base showing that non medical personnel can successfully administer Depo injectables to women at the community level and hence encourages this approach (WHO, USAID \& FHI 2009).

Access to skilled care during delivery: Ensuring skilled attendance of all births, backed by emergency obstetric care when needed, would reduce maternal deaths by about 75 percent (UNFPA, No Woman Should Die Giving Life, Facts and Figures 1). Primary care facilities should be upgraded to be able to provide attended delivery services. This requires refresher training for staff, especially on management of normal deliveries, active management of third stage of labour (AMTSL) and identifying danger signs during delivery. Moreover, life-saving drugs (e.g. magnesium sulfate, oxytocin and misoprostol) should be available in every facility in addition to basic equipment.

Shortages of trained medical staff in rural areas or in some states (e.g. South Darfur), limits access to skilled care during delivery. The Government of Sudan should consider policies to encourage health care providers to work in remote areas, for example, by paying them a salary supplement or exempting them from taxes. However, with most deliveries in Sudan taking place at home, the Government should focus on building the capacity of village midwives. It is commendable that $\mathrm{MOH}$ / Sudan has reopened midwifery schools and has revised their training curriculum to ensure adequate knowledge and skill acquisition (Federal Ministry of Health, Directorate General of Preventive Medicine and Primary Health Care, 2009).

VMWs need to be integrated into the health care system, receive refresher training, medical supplies and be closely monitored by state supervisors to ensure adherence to minimal acceptable standards of practice. Policies need to be revised to allow VMWs to administer life-saving drugs like magnesium sulfate and misoprostol. The latter has long been recognized as a safe and efficacious drug for controlling postpartum hemorrhage (PPH). Its low cost, ease of administration (rectal, oral or sublingual) and stability in tropical climates make it an ideal solution for home births. Research from other countries has shown that even illiterate traditional birth attendants (TBAs) can successfully use misoprostol for the prevention of postpartum hemorrhage (Prata et al., 2005, Wal Raven and Weeks, 1999). Operations research can help policy makers in Sudan in identifying best ways to train and monitor VMW's performance.

Rapid access to quality EMOC: General and district health facilities need to be upgraded and every effort must be made to increase access to EMOC as part of basic medical care. Providers in secondary and tertiary care hospitals need training in service delivery protocols on CEOC including instrumental delivery, C-section and postabortioncare. Also, every general and district hospital should have a blood bank, ICU and NICU. 


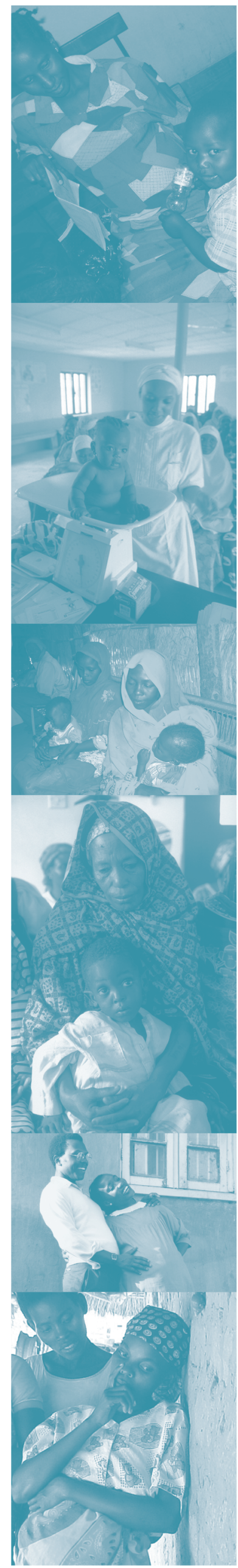

Referral of emergency cases to higher levels of care poses a challenge due to limited access to telecommunication and a shortage of transportation. There have been recent interventions that used mobile phones to provide community health workers in remote settings with advice from medical professionals on diagnosis and treatment of medical conditions (e.g. Vital Wave Consulting, 2009). Although use of this technology in health care is in its early stages, it holds great potential for saving lives of mothers and children in developing countries. Moreover, discussion about planning for birth preparedness should be an integral part of antenatal care consultations, so that women and their families know about the warning signs, what actions to take and where to go in case of emergency.

In the meantime, $\mathrm{MOH} / \mathrm{Sudan}$ should consider expanding services that are provided at primary health care facilities to include BEOC. Primary health care facilities should be able to provide assisted deliveries, postabortion care and prereferral management of complicated cases (e.g. administering IV fluids). Manual Vacuum Aspiration (MVA) and misoprostol can be used to manage incomplete abortions in primary health care settings as they are safe, effective, inexpensive, and can be performed without general anesthesia (Prataet al., 2009). Moreover, in situations where a physician is not available, nurses and nurse midwives should be trained and allowed to manage obstetric emergencies as they constitute the largest proportion of health personnel attending deliveries, especially in primary care facilities. Examples from Mozambique and Malawi indicate that nurses have successfully provided basic and even comprehensive emergency obstetric care (Pereira et al., 1996; Fenton; Witty \& Reynolds, 2003).

In conclusion, improving quality of maternal and neonatal health services requires interventions that are quickly achievable, sustainable and cost-effective. It needs concerted efforts of governments, international organizations, civil society, the media, corporate sector and others to identify and implement cost effective solutions that would save lives of thousand mothers and newborns in Sudan. 


\section{R E F E R E N C E S}

Abdel-Tawab, N.; Suliman, E.; and Nada, K. Forthcoming. A Situation Analysis of Reproductive Health Services and Utilization Patterns in Gadarif State, Sudan. Final Report. Cairo, Egypt: Population Council.

Abdel-Tawab, N.; Suliman, E. and Nada, K. Forthcoming. A Situation Analysis of Reproductive Health Services in Gezira State, Sudan. Final Report. Cairo, Egypt: Population Council.

Abdel-Tawab, N.; Loza, S. Zaki, A. 2008. Helping Egyptian Women Achieve Optimal Birth Spacing Intervals through Fostering linkages between Family Planning and Maternal / Child Health Services. FRONTIERS Final Report. Cairo, Egypt: Population Council.

El-Rabbat, M. et al. Forthcoming. A Situation Analysis of Reproductive Health Services in North Kordofan State, Sudan. Final Report. Cairo, Egypt: Population Council.

Federal Ministry of Health, Directorate General of Preventive Medicine and Primary Health Care. 2009. Roadmap for Reducing Maternal and Newborn Mortality in Sudan (2010-2015). Khartoum, Sudan: Federal Ministry of Health.

Fenton, PM; Whitty, CJ; Reynolds, F. 2003. "Caesarean section in Malawi: Prospective study of early maternal and perinatal mortality." British Medical Journal ; 327(7415: 587).

Sudan Government of National Unity and Government of Southern Sudan. 2006. Sudan Household Health Survey (SHHS) - 2006. Khartoum: Sudanese Central Bureau of Statistics / Southern Sudan Commission for Census, Statistics and Evaluation.

Khan, ME. et al. 2008. Promoting Healthy Timing and Spacing of births in India through a Community-Based Approach. FRONTIERS Final Report. New Delhi, India: Population Council.

Kinaro, J. et al. 2009. "Unsafe abortion and abortion care in Khartoum, Sudan. Reproductive Health Matters, 17(34):71-77.

Mowafi, M. et al. Forthcoming. A Situation Analysis of Reproductive Health Services in Kassala State, Sudan. Final Report. Cairo, Egypt: Population Council.

Mowafi, M. et al. Forthcoming. A Situation Analysis of Reproductive Health Services in Khartoum State, Sudan. Final Report. Cairo, Egypt: Population Council. 


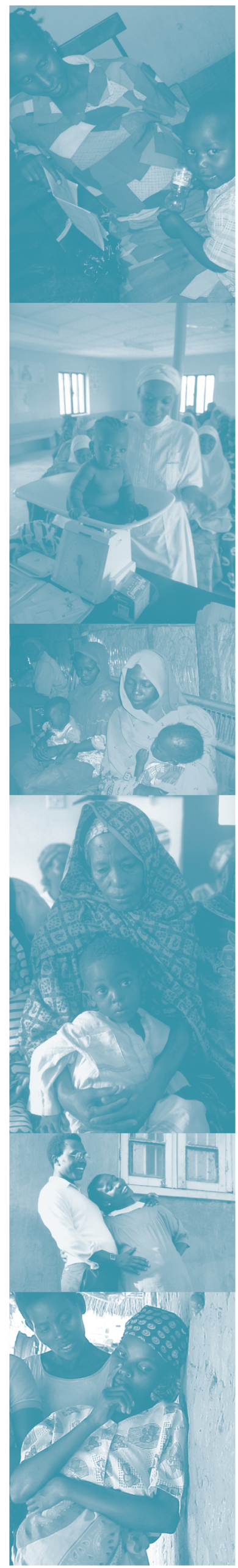

Mowafi, M. et al. Forthcoming. A Situation Analysis of Reproductive Health Services in South Kordofan State, Sudan. Final Report. Cairo, Egypt: Population Council.

Pereira, C.; Bugalho, A.; Bergestrom, S; Vas, F. Cotiro, M. 1996. A comparative study of Caesarean deliveries by assistant medical officers and obstetricians in Mozambique. British Journal of Obstetrics and Gynecology ; 103(6):508-12.

Prata, N.; Sreenivas, A.; Vahidnia, F. and Potts, M. 2009. "Saving maternal lives in resource poor settings: Facing reality". Health Policy (89): 131-148.

Prata, N.; Mbaruka, G.; Campbell, M. 2005. Using the Kanga to measure postpartum blood loss. International Journal of Gynecology and Obstetrics; 89(1):49-50.

Suliman, E. et al. Forthcoming. A Situation Analysis of Reproductive Health Services in South Darfur State, Sudan. Final Report. Cairo, Egypt: Population Council.

UNFPA, "No Woman Should Die Giving Life": Facts and Figures 1. Link:http:// www.unfpa.org/safemotherhood/mediakit/documents/fs/factsheet1_eng.pdf (accessed on February 20, 2010).

Vernon, Ricardo. 2008. Meeting the family planning needs of postpartum women. FRONTIERS Program Briefs No. 10. Washington, DC: Population Council.

Vital World Consulting. 2009. Health for Development: The Opportunity of Mobile Technology for Health Care in the Developing World. Washington, D.C. and Berkshire, UK: UN Foundation - Vodaphone Foundation Partnership.

Walraven, G., Weeks, A. 1999. "The role of (traditional) birth attendants with midwifery skills in the reduction of maternal mortality." Tropical Medicine and International Health; 4(8): 527-9.

World Health Organization. 2004. Making pregnancy safer: The critical role of the skilled attendant. A joint statement by WHO, ICM, and FIGO. Geneva: Department of Reproductive Health and Research, World Health Organization.

World Health Organization, Department of Making Pregnancy Safer (2009). WHO recommended interventions for improving maternal and neonatal health. Geneva: World Health Organization.

World Health Organization, U.S. Agency for International Development, Family Health International (FHI). (2009). Community-Based Health Workers Can Safely and Effectively Administer Injectable Contraceptives: Conclusions from a Technical Consultation. Research Triangle Park (NC): FHI. 
West Asia and North Africa (WANA) Regional Office

59 Misr Helwan Agricultural Road, Maadi Cairo, Egypt

Tel: +20 22525 59658/7/

Fax: +20 225255962

E-mail: info.mena@popcouncil.org
Sudan Country Office Building 13, Block 3/Y, Khartoum 2, Khartoum, Sudan, Tel.: +249 183564358

E-mail: infosudanoffice@popcouncil.org
Population Council / Headquarters One Dag Hammarskjold Plaza New York, New York 10017 USA Tel: +1 2123390500

Fax: +12127556052

E-mail: pubinfo@popcouncil.org Website:www.popcouncil.org

The Population Council is an international, nonprofit, nongovernmental organization that conducts research worldwide to improve policies, programs, and products in three areas: HIV and AIDS; poverty, gender, and youth; and reproductive health. 